\title{
Soberanía y competición política - 1808-1830 Unos problemas y unas definiciones
}

\author{
Antonio Annino $0^{1 ; 2 *}$
}

\section{Resumen}

El artículo tiene por objeto reflexionar sobre cómo debemos entender el processo que eclosiona en Iberoamérica tras los acontecimientos de 1808 en la Peninsula, abriendo um ancho campo de disputa y competición política por la instalación y el control de nuevos gobiernos soberanos. Considerando que términos como "ambivalencias", "sincretismo", "aporías", "contradicciones" etc. son inapropiados para definirlo, se argumenta la conveniencia de renunciar a entender la dinámica legal e institucional que entonces se experimenta por medio de um contraste estéril entre modernidad y tradición. El trabajo defiende que el punto real fue que las elites que alteraron radicalmente el campo de la política a partir de 1808 no pusieron en discusión la legalidad más bien la implementaron, para luego sufrir en carne propia las consecuencias.

\section{Palabras-clave}

Iberoamerica - independencias - legalidad - modernidad - siglo XIX.

${ }^{1}$ Universidad de Florencia, Florencia - Itália

${ }^{2}$ CEHIS Universidad Externado de Colombia, Bogotá - Colombia

* Profesor Catedrático en la Facultad de Ciencia Política de la Universidad de Florencia y profesor afiliado en la División de Historia del Centro de Investigación y Docencia Económicas en la Universidad Externado de Colombia. E-mail: anninovondusek@gmail.com. 


\section{Sovereignty and political competition - 1808-1830 Some problems and some definitions}

The article aims to reflect on how it must understand the process occurred in Latin America following the events of 1808 in the Peninsula, opening one widefield of disputes and political competition for the installation and control of new sovereign governments. Considering that terms as "syncretism", "aporia", "ambivalence", "contradictions" etc. areinappropriatetodefineit, arguestheconveniencetonotunderstand the legal and institutional dynamics which were then experienced by a sterile contrast between modernity and tradition. The work argues that the real point was that elites, which radically altered the field of policy from 1808, did not put in discussion the legality but implemented it, then suffering the consequences in their own body.

Latin America - independence - legality - modernity - 19th century. 
Las revoluciones atlánticas cambiaron en muchos países las formas de lasluchas políticas. El proceso no siguiómodelos o planes pensados antes sino que nació y se desarolló sobre la marcha. ¿Quién, por ejemplo, podía imaginar en la época dorada de los salones franceses que, entre 1789 y 1791 , el territorio de la nueva nación cayera en manos de centenares de clubes, directas emanaciones de los grupos que lucharon en la Asamblea? Repárese también en un dato: las nuevas elecciones no regularon ni determinaron los éxitos de los dramáticos enfrentamientos que marcaron los rumbos dela revolución ${ }^{1}$. La nueva representación no logró encauzar las luchas, y el mítico "pueblo" se quedó introuvable por mucho tiempo, y no sólo en Francia ${ }^{2}$. El liberalismo fueun proyectoquepretendía solucionarlos dilemasheredados de la disolución del Antiguo Régimen, pero vale la pena recordar que en la vieja Europa las "revoluciones liberales" triunfaron sólo trás los eventos de 1848 y sólo en aquellos países donde se dió una alianza entre liberales y monarquías. En aquel continente, republicanismos y liberalismos fueron enemigos mortales a lo largo de todo el siglo XIX, y así lo fueron igualmente los democráticos y los liberales.

En el ex-orbe hispánico la historia fue muy diferente. Por razones quetodavíaloshistoriadores no hemoslogradoaclarardefinitivamente, el liberalismo cobró una carga radical absolutamente inimaginable en otras áreas occidentales mientras que el triunfo republicano en América fue absoluto e irreversible, otro dato cuya explicación permanece abierta. No cabe duda, por ejemplo, que las independencias costaron sangre - y mucha - mientras que la instauración de la republica fue sangrienta y tuvo - en pocas palabras - una aceptación casi masiva, algo a primera vista sorprendente después de tres siglos de indiscutible lealtad a la monarquía. Sin embargo, llama la atención el hecho de que el consenso hacia la república no despertó en su mo-

1 GUENIFFFEY, Patrice. Le nombre et la raison. La Révolution Française et les élections. Prefacio de François Furet. 1993. Dix-huitième Siècle, $n^{\circ} 26,1994$. p. 604-605. (Economie et Politique). 2 ROSANVALLON, Pierre. Le peuple introuvable. Histoire de la souveraineté du peuple en France. Paris: Collection Bibliothèque des Histoires, 1998. 
mento un debate acerca del"ser republicano"comparable a los que se dieron en Francia o Estados Unidos en el mismo curso de sus revoluciones. Lo que, sí, se debatió desde el primer momento fue el formato del gobierno republicano, mientras que su"ser"fue discutido hacia la mitad del siglo, cuando los conflictos entre liberales y conservadores, centralistas y con/federalistas se tornaron - ahora sí - sangrientos. De manera que hay un primer republicanismo cuya base consensual espera todavía una explicación. Otro dato sumamente llamativo es el consenso masivo hacia el constitucionalismorepresentativo, en todas sus declinaciones, y la profundidad social de las movilizaciones políticas a su alrededor. Los estudios de etnohistoria han demostrado, por ejemplo, la participación política de las comunidades indígenas, siempre en favor de los"sagrados códigos", algo que para un europeo de la época hubiera parecido inexplicable y por fuera del"progreso"3. Porsupuesto,estaafirmaciónnominimiza en absolutolacuestión indígena en cuanto tal, se trata más bien de enfocarla en la lógica histórica de la interacción plurisecular entre el mundo indígena y el Occidente, algo que permite superar los estereotipos del "victimismo" pasivo y/o únicamente "resistente" y recuperar para nuestro sentido histórico el largo proceso que desde la conquista permitió al indio sobrevivir utilizando recursos occidentales para defenderse del mismo Occidente ${ }^{4}$.

3 Véase a este propósito CHIARAMONTI, Gabriella. Suffragio e rappresentanza nel Peru dell 800. Gli itinerari della sovranita (1808 1860). Turin: Otto ed., 2003; BELLINGERI, Marco. Ceti ed etnie in Yucatan. Costituzione sviluppo e crisi de una formazione interetnica fra sette e ottocento. Torino: Celid, 1990; DEMELASM, Marie-Danielle. La invención política: Bolivia, Ecuador, Perú en el siglo XIX. Lima: Estudos historicos, 2003; ENRIQUEZ, Lucrecia Raquel. Antonio Annino, Silencios y disputas en la historia de Hispanoamérica. Historia, Santiago, vol. 49, n. 1, p. 7-9, jun. 2016. Disponible en: <https://scielo.conicyt.cl/scielo.php?script=sci_arttext\&pi$\mathrm{d}=$ S0717-71942016000100011\&lng=es\&nrm=iso >. Acceso en: 09 jul. 2018. http://dx.doi. org/10.4067/S0717-71942016000100011.

4 Véase CARMAGNANI, Marcello. L'altro occidente. L'America Latina dall'invasione europea al nuovo millennio. Torino: Einaudi, 2003. En los ultimos años, el tema de la occidentalización llama cada vez más la atención de varias disciplinas. Recordamos que el concepto nació en la Inglaterra victoriana con un sentido obviamente eurocéntrico y así se quedó por mucho tiempo hasta la redefinición actual. En el caso de los estudios americanistas la etnohistoria tuvo un papel destacado.Véase, por ejemplo, GRUZINSKI,Serge.La colonisation del'imaginaire.Societésindigènes 
Estas anotaciones tienen mucho que ver con nuestro tema, pero antes de seguir se necesitan unas aclaraciones conceptuales. No es lo mismo decir "lucha política" que "competición política", la primera es una definición descriptiva mientras que la segunda es una definición analítica. Privilegiar la "lucha" significa estudiar los actores mientras que meterse en el campo de la"competición"implica de entrada plantearse unas preguntas metodológicas, como por ejemplo, ¿cuál fue la lógicaquearticulólasluchas? ¿cuálesfueronlosrecursos? ¿cuálesfueron lasreglas?Estaspreguntassuenanobviassinuestrosobjetosdeestudio fueranlas democraciasmodernasqueprescribenlasrespuestasypermiten pensar en la competición política como un campo de estudio en sí. Son mucho menos obvias si nos enfrentamos con sociedades de Antiguo Régimen donde el concepto mismo de "competición" no existía ni podía existir por evidentes razones. Por supuesto, sería imposible estudiar el tema sin tener un conocimiento razonable de las luchas y delosactores,peronocabedudaquehoydisponemosdeunacantidad notable de obras al respecto.

Existen además otras razones. Muchos protagonistas destacados deaquellas décadas -empezando por Bolívar-percibieron la competición política como algo anómalo, anárquico, peligroso para el nuevo orden que pensaron edificar, un síndrome heredado por las primeras generaciones republicanas. Lograr la estabilidad política en el siglo XIXfueun rompecabezas angustiante, peroel síndromedeldesencanto, aquel que Sarmiento supo expresar magistralmente, fue un fenómenocultural mucho más complejo, que necesita una mirada más allá de América. El desencanto por los insuficientes, y a veces dramáticos, logros de la modernidad política y social fue compartido por todos los países mediterráneos. En Italia, por ejemplo, cuando los piemonteses lograron incorporar al sur en 1861, la imagen que pintaron fue de una gente "bárbara" y "africana" (casi "sarmentina"), un juicio que perduró hasta bien entrado el siglo XX. Incluso Gramsci - a su manera - se

et occidentalizatión dans le Méxique español, XVI-VIII siécles. Paris: Collection Bibliothèque des Histoires, Gallimard, 1988. 
ocupó de la famosa "cuestión meridional" en su esfuerzo por dar una explicación nueva de loslímites del Risorgimento, yla conocida novela "El gattopardo" es una versión brillante y sublimada del eterno desencanto italiano. En la Rusia zarista el liberalismo fue siempre aplastado, pero la famosa disputa entre "slavófilos" y "occidentalistas" adquirió un valor "universal" gracias a la altísima calidad de sus protagonistas, desde Puskin hasta Tolstoi.

En fin, el síndrome del desencanto no fue un fenómeno americano sino internacional, un efecto no previsto, si se quiere, del gran cambio cultural promovido por las revoluciones atlánticas y antes por lallustración (5) en aquellas largas décadas que marcaron la transición del Siglo de las Lucer al de la Nación (y de su Historia) se consolidó una nueva idea de libertad civilizadora, una idea no tan "universal" como la dibujaron sus intérpretes. Mejor dicho: la nueva polis fue a la vezincluyenteen susvalores peroexcluyenteen susrequisitos, porque no todos los pueblos tuvieron el derecho historico de entrada, y este potente paradigma fue compartido por todas las élites occidentales, por una parte y por otra del Atlántico. La "Historia del tribunal del mundo"nofuesólounaimagen literariadeunospensadoresalemanes sino un metro operativo para medir los alcances de la acción política. No a caso el desencanto de Bolivar nació de sus reflexiones históricas acerca del pasado americano, de lo que el llamó por primeta vez"herencia colonial".

Otra razón para justificar nuestro tema es lo que podríamos llamar la "opacidad" de las revoluciones atlánticas. Sus enormes potencialidades, su proyección "épocal", la vastedad de sus ecos dibujaron también un paisaje de incertidumbre y de dramáticas experiencias constitucionales. Nada de lo que fue proclamado estaba aclarado, no se sabía bien cómo articular en forma coherente la soberanía con la representación,yéstaconlosnuevosderechosdelhombre,nielmismo voto con la proclamada "voluntad general". A lo largo del siglo XVIII europeo el debate acerca de la "constitución inglesa" fue central, pero cuando Montesquieu teorizó a su manera el principio de la división de los poderes pensaba en la posibilidad concreta de reformarel Antiguo Régimen monárquico sin destruirlo, ubicando en dos cámaras el po- 
der nobiliario y el poder del estado llano. Es decir que la tan celebrada fórmula montesquieana deeste clásico autorapuntabaa institucionalizar poderes sociales y no poderes "funcionales", como diría hoy un constitucionalista. A pesar deléxito de aquellas pocas páginas sobrela división de los poderes, el problemacentral dela obra deMontesquieu fue - como sugiere el título - la naturaleza de las leyes y no la de la representación que,sí,fueel dramático dilema dela revolución francesa. Su desarollo sacó a la luz la dificultad casi insuperable de articular la "voluntadgeneral"conlanuevarepresentación, un problemaquedejó atrás Montesquieu, a Rousseau, y a la "constitución inglesa". Quizás ese dilema irresuelto explique - por lo menos en parte - la imposibilidad de encauzar las luchas políticas en una competición reglamentada. Lo que, sí, fue objeto de debates y experimentos contínuos fue el voto, que sinembargo-comoya hemos recordado-nunca arreglólas luchas. Las razones de este deficit no sólo francés pueden ser que sean muchas y diferentes de caso en caso, como muestra el contínuo debate historiográfico, pero estamos convencidos que la explicación más razonable es cultural: en el imaginario político de la época el voto no teníaquesercompetitivo.Hayalgomásquemereceatención:ningunode los grandes pensadores liberales del siglo XIX teorizó la competición electoral como un principio ineludible para legitimar la representación: la competición se podía por supuesto dar - como en efecto se dió en todas partes - pero sin llegar a ser pensada como un valor de liber$\operatorname{tad}^{5}$. El histórico paso al voto competitivo y libre (en aquel sentido) fue una empresa cultural de las democracias del siglo XX a lo largo de sus luchas mortales en contra de los totalitarismos. La cuestión del voto competitivo es una de las tantas que obligan a pensar que entre liberalismo y democracia las diferencias históricas fueron radicales, a tal punto que necesitaríamos-nosotros los historiadores-recuperar

5 La bibliografía sobre la historia electoral del siglo XIX es enorme porque los estudios tienen casi medio siglo de existencia. Un excelente análisis critico se encuentra en ROMANELLI, Raffaele (dir.). How did they become voters? The history of franchise in modern European representation. La Haye: Kluwer Law International, 1998. 
en toda su complejidad la autonomía del siglo XIX frente al XX. La democracia que conocemos es hija de los millones de muertos del"siglo breve" y no del liberalismo del siglo XIX.

La América hispana compartió a su manera los grandes dilemas y retos delas revoluciones atlánticas. Lasluchas políticas siguieron siendo destabilizantes a lo largo del siglo XIX, no siempre porque hubo actores "antisistema", y sin embargo la governance fue siempre dificil. Las explicaciones Ilenan bibliotecas y hasta podría verse como algo atrevido presentar unas hipótesis al respeto. Por cierto loes, yestamos concientes, peroloúnico que podemos decires quelas reflexionesque vamos a presentar en las paginas que siguen no son un fruto ocasional sino el resultado de un trabajo de años. Como ya dijimos, las investigaciones de historia política y social han adelantado enormemente el conocimiento y hasta han cambiado radicalmente la imagen de las independencias. Asíque la motivación basica para proponer el tema de la competición política, como un campo distinto del de las luchas políticas, viene de la situación actual de los estudios. Quizás estamos en condiciones deempezar una reflexión conceptual paralograr-porasí decirlo-"poner cada cosa en sulugar". Por el mismo motivo pensamos aclarardeentradanuestrahipótesis:lasinvestigacionesnosconvencieron enforma totalmenteimprevista quelasluchas políticas entre 1808 y 1830 tuvieron una naturaleza legal e institucional, y que el síndrome deldesencantocancelóestemagnodatodedosagendas:aquelladelas élites y aquella de la historiografía, que incorporó la primera a la segunda.Perolacuestión noseacaba conestedato.Loqueintenteremos reconstruir sumariamente en las páginas que siguen es el punto crucial: lo legal e institucional de las luchas fueron el fruto de una lógica que se puede declinar con todos los términos que la historiografía fue capaz de inventarse para definir su desencanto:"ambivalencias", "sincretismo", "aporías", "contradicciones" etc., todo un vocabulario que a fin de cuenta es hijo de la verbosa y estéril disputa entre modernidad ytradición. El puntorealesquelasélitesquemodificaron radicalmente el campo de la política a partir de 1808 no pusieron en discusión esta legalidad sencillamenteporquelaimplementaron, paraluegosufriren carne propria las consecuencias. Por último una aclaración debida:no 
vamos a tratar de las guerras, sin duda un límite muy grave. El punto es que este tema está en una condición parecida a la de las "luchas políticas", sabemos mucho de éstas pero nada de sus reglas, de sus recursos políticos (que siempre existen), de sus lógicas institucionales (tambiénexistentes). Enestemomentoestamosinvestigando,perono estamos a la altura de proponer algo sensato.

\section{La cuestión de la soberanía:}

retroversión, redistribución, revolución

Los estudios sobre las luchas políticas sugieren que hubo dos formas de competir políticamente: por una parte, la lucha para poder decidir sobre los demás - es decir la forma clásica - y por otra, hubo también una lucha para poder decidir sobre símismos, con el objetivo de tener más poder frentea los demás. Nos referimos en este caso a los actores colectivos, a los cuerpos del gran cuerpo de la república ubicada "entre Dios y el Rey"6, y no para minimizar el papel de los grupos dirigentes sino para señalar una vez más el protagonismo de aquellos cuerpos territoriales que en forma general se les llamaba "pueblos", término que no define sino que identifica, lo cual es otra cosa. Es cierto que el complejo normativo de la Monarquía Católica se preocupó a lo largodesuhistoria de definirlos requisitos paraque un poblado pudiera acceder al estatus de "pueblo", como por ejemplo tener una iglesia, hacer parte de una parroquia, tener recursos naturales suficientes etc., pero lo que cuenta al fin y al cabo es que en base al estatus adquirido el nuevo sujeto territorial entraba en el mundo de los privilegios y por lo tanto de nuevos recursos legales: tener una personalidad jurídica propia para promover sus intereses frente a la justicia de la Corona, la posibilidad de tener un cabildo proprio, y last but no least tener tierras comunales para incrementar sus bienes. Ni podemos olvidar aquí un dato filológico: en el orbe hispanico el término"pueblo"es la traducci-

6 Véase LEMPERIERE, Annick. Entre Dieu et le roi la république (Trad. esp.: Entre Dios y el rey: la república. La ciudad de México de los siglos XVI aI XIX). México: Fondo de Cultura Económica, 2013. 
ónlineardel originariopopulus queen las primerasépocas delimperio cristiano definía las parroquias, algo que tiene que ver con el nuevo orden constitucional después de 1808 , cuando-como sabemos - los distritoselectorales delasprimerascartasfueron precisamentelas parroquias.Enfin,los"pueblos"fueron desdesiempreunainstitución política de la monarquía bajo una doble jurisdicción, la cívil y la eclesiástica, un dualismo que se quedó en las repúblicas independientes.

De manera que hay un primer dato históricamente significativo para nuestro tema: no sólo los pueblos fueron un sujeto legal en el desigual y plural universo de la monarquía, sino que sus tantas movilizaciones a partir de 1808 - bajo varias formas - constituyen otros tantos procesos institucionales que tenemos que recuperar para estudiar la competición política y su naturaleza. Las movilizaciones, sí, fueron fenomenossociales, perosupesopolíticoestuvosiempreenrepresentar yrepresentarsecomoactoresdeporsíinstitucionales, undatoquenadie en aquel mundo en transformación puso nunca en discusión. De manera totalmente distinta se plantea la cuestión linguística acerca de los "pueblos de la monarquía". Una de las características salientes del idiomadelosantiguosregímeneshasidosiempresufluidezpolisémica que poneno pocos problemas a nuestros paradigmas que buscan"definir" las "cosas" en forma absoluta. El poder administrativo moderno - con sus códigosy su concepción de la ley-generó un idioma político autosuficiente para garantizar las autonomías del estadoy de la sociedad. Es lo que Marx llamó "la potente empresa de abstracción" que permitióconsolidarunanuevaforma de dominación política, fundada sobre el principio de "definir para gobernar". Desde entonces la "abstracción" de la política moderna ha sido un tema de disputas contínuas que siguen hoy aún más fuertes que nunca. No cabe duda, sin embargo, que sin aquella potente empresa el principio de la igualdad no sehubierapodidoimplantar.Definirparagobernar,oparacompetirpor el gobierno, fue la lógica del paradigma linguístico que se contrapuso aldelosantiguosregímenes:identificarparagobernaryasígarantizarla desigualdad en forma "justa", dando "a cada uno lo suyo" con base en el antiguo y cristianísimo principio de la justicia redistributiva. 
Sin entrar en los pormenores de esta temática tan compleja, es suficiente aquí señalar que se identificaba un caso concreto en el universo delos posibles (y probables) pormedio de una sintaxis quesefundó enelgranepistemedelasimilitudo,comodiríaFoucault.Lavariabilidad semántica del término "pueblos" viene de ahí: los pueblos son como almas, en el caso de los "pueblos de la monarquía", y al mismo tiempo son como "cuerpos de la república", si se quiere identificarlos como otros tantos sujetos políticos, cada uno con sus privilegios y derechos. La misma lógica semántica valía para los subditos de la monarquía, que no fueron nunca "individuos" sino "personas", cada una con diferentes estatus al mismo tiempo (alma, padre de familia, comerciante, empleado público, indio de república, casta etc.). El universo de la república sequedósiempre incognosciblea priori porquefuesiempre una república casuista de "personas", cuerpos y/o subditos, no de "individuos"nacidos como tales y como tales definibles". A fin de cuenta, la única subjetividad "en sí" fue la de "alma" en el sentido teológico. Nos interesa destacardos puntosa partirdenuestra sumaria descripción: el primero es que a falta de "definir y clasificar" sí se pudo siempre "identificar y ubicar" un caso para reconocerlo frente a los demás; y el segundo es que la vía maestra para identificar - o luchar para ser identificado - fu siempre la vía judicial, también en política. Como veremos, estos dos puntos son cruciales para nuestro tema.

Porsupuesto,enlaépocacarolinalasimilitudoepistemológicafueel campo debatalla de losilustradoshispánicos,yCampomanes logróen 1771 una notable reforma de la enseñanza universitaria, sin embargo en 1794 Carlos IV la mutiló debido a los eventos franceses, dejando las novedades de las ciencias matemáticas y naturales bien separadas de los demás saberes que pudieran parecer peligrosos paralas instituciones civiles y religiosas. La victima más ilustre fue la cátedra de Derecho Natural y de Gentes que la ilustración carolina había impulsado en la

7 Véase sobre este tema en el caso de la carta gaditana: CLAVERO, Bartolome. Cádiz 1812: Antropología e historiografía del individuo como sujeto de constitución. Quaderni fiorentini per la storia del pensiero giuridico moderno, vol. 42, n 1, 2013, p. 201-279. ISSN 0392-1867. 
Península y en América. El punto es que muchos de los intentos ilustradoseuropeossequedaronenesta situación-el ejemplomásilustre fue la alemana a pesar de sus extraordinarios logros filosóficos - hasta cuandolasrevolucionesatlánticas(ylasguerrasnapoleónicas)sacaron a la luz esta situación inconclusa. El orbe hispánico no escapó a este destino, y su rumbo fue decidido por la larga agonía de la monarquía en las dos orillas del Atlántico.

Enestemarcohistóricoyalavezepistemológicotenemosqueubicar la cuestión de la competición política porque sus recursos, reglas, instituciones, hastasussíntomas dedesencanto,fueronfenómenosque tuvieronunalógicapropia, nocomparableconlasdemásrevoluciones de la época. El problema pendiente es precisamente esta "otra" racionalidad que en muchos casos fue percibida como ajena a los dictámenes de la nueva polis, lo cual implica enfrentarse otra vez con temas de sobraconocidosyquesinembargomerecenserpensadosunavezmás. Empezamosentonces con el gran tema dela soberanía porque-como es bien sabido - fue una cuestión sumamente controvertida en lo político no sólo en las dos décadas que siguieron a las noches de Bayona sino hasta bien entradas las nuevas repúblicas ${ }^{8}$. Hubo-es cierto - una lucha entre soberanías desde el primer momento de la crisis de la monarquía. Sin embargo este fenómeno tan proprio del orbe hispánico no se puede analizar como un conflicto entre "autonomismo" $y$ "centralismo" o"federalismo", como si fueran opciones claras desde 1808. $\mathrm{Ni}$ se puede decir que estos términos se quedaron aclarados en las décadas siguientes. Las primeras cartas, sí, dibujaron regímenes "federales"o "centralistas" y las luchas fueron encarnizadas entre los dos bandos, pero las formas de movilización y las lecturas que se dieron a estos términosfueron muy diferentes en cada bando, máximeen el así

8 Imprescindible la obra de MOLINA, Eugenia. Lenguaje y revolución: Conceptos políticos clave en el Río de la Plata, 1780-1850. Rev. Hist. Derecho, Ciudad Autónoma de Buenos Aires, n. 40, dic. 2010. Disponible en: <http://www.scielo.org.ar/scielo.php?script=sci_arttext\&pid=S1853-17842010000200010\&lng=es\&nrm=iso >. Acceso en: 09 jul. 2018. 
dicho "federalista". Esta cuestión es central para entender la naturaleza de la competición política y la cuestión misma de la soberanía.

La pluralidad de lecturas de categorías políticas más o menos "modernas"se inscribe en los orígenes de la cuestión de la soberanía. El trend de las revoluciones atlánticas fue transferir la soberanía de un centro antiguo a otro nuevo, de las monarquías a las asambleas representativas. En pocas palabras la transferencia fue "horizontal" por así decirlo, mientras que en el orbe hispánico fue "vertical", de la Corona a los "pueblos", algo tan imprevisible como la misma abdicación de los Borbones. Hemos ya enfatizado en otros trabajos - y no sólo nosotros - la completa ilegalidad de Bayona, y cómo sólo la necesidad de evitar las consecuencias de otra noche de Varennes salvó el principio monárquico y con él las posibilidades de reformarlo profundamente de una forma o de la otra, aunque la caída "vertical" de la soberanía abrió otroescenario imprevisible. Aquíse plantean dos preguntas cruciales para los historiadores: ¿cómo explicar el éxito aplastante de la "retroversión", es decir, de un concepto que nunca fue anunciado ni teorizado? Invocar la tradición neoescolástica no sirve de mucho, porquelostresfamosos pactostuvieron siempreuna naturalezateológica absoluta y no relativa, en el sentido que su operatividad política nunca fue enunciada, y mucho menos hasta el punto de conjeturarcomo posible y concreta la "retroversión".

La segunda pregunta sale de la primera y es aún más crucial: ¿cuál idea de la soberanía aterrizó en los pueblos? ¿Es posible que fuera ya conocida cómo para generar un consenso tan amplio a pesar dela inéditavacatioregis? El paradigmahistoriográficonacidodelas revolucionesatlánticasnunca tuvo dudasal respeto:la soberaníarevolucionaria de las asambleas era la legislativa, expresión de la"voluntad general" odelosrepresentantes deloscolonialestatesnorteamericanos.Sinembargo, este tipo de soberanía resultó de la lógica de los eventos que la configuraron: en la Francia de 1789 la soberanía de la Asamblea fue la legislativa porque el ejecutivo se quedó - junto a la justicia - en el rey. El primer acto revolucionario fue dividir los poderes, y para los moderados ésta fue la "verdadera" revolución "a la inglesa". En el norte de Américalosestatesya contaban con las divisiones delos poderes antes 
de la revolución. El caso hispánico siguió otra lógica, y por lo tanto no podemos escapar a nuestras preguntas. Repárese entonces en un hecho clave: antes la soberanía se reubicó verticalmente en "Ios pueblos"ydespuésse intentóreubicarla en unas asambleascon divisiones de poderes, una empresa totalmente inédita y mucho más difícil de lo imaginado por los actores y por la misma historiografía, si seguimos utilizando únicamente el paradigma anglo-francés. Ni podemos realmente decir cuándo y cómo esta empresa logró consolidarse más allá de las proclamaciones formales. Lo que, sí, sabemos de forma certera es que a lo largo del siglo XIX en la América hispánica coexistieron dos conceptos: "soberanía de los pueblos" y "soberanía del pueblo", un dualismo que nunca fue radicalmente conflictivo - como podría parecer hoy-y que constituye la punta de un iceberg muy profundoy extenso, donde incluimos el tema de la competición política.

Regresamos ahora a nuestro problema. Si el concepto de "retroversión"tuvo tanto éxito, si nunca fue puesto en tela dejuicio, sifue capazdeactivarlaacción políticaotorgándoleunsentidodelegitimidad, entoncestenemosqueadmitirqueelconceptodesoberaníanocambió al desplomarse "en los pueblos", al revés de lo que pasó en las demás revoluciones atlánticas. El punto es que no es fácil definir qué era la soberanía de la persona del rey católico en 1808. Mejor dicho, para "definir"tenemosque manejarvarios enfoques, recordandoen primer lugarquenuncaexistióunadoctrinacoherenteyautosuficienteacerca deloquedurantelossiglossellamódediferentesmaneras, señoríoreal, meroimperio,majestad,supremajurisdictio,supremapotestas,plenitudopotestas, poderíoabsoluto.Laplurisecularyabundantetratadísticasobrelasfacultadesabsolutasdelmonarcaconstituyeunacanteradeargumentaciones muy plural, que en cierto sentido "acompañó" el desarollo de la monarquíahispanaen susdiferentesetapas deconsolidación.Decimos "cantera" porque - a pesar que hubo líneas de pensamiento a veces divergentes-nunca se pensó que una tesis podía abrogar otra en forma absolutay definitiva. Aquella tratadística tuvo siempre una naturaleza jurisprudencial, cumulativa, una lógica no diferente a la que organizaba la producción del derecho. Sin embargo, este universo pluralista tuvosusfronterasquealavezindicaban los límites del poderíoabsoluto 
de los monarcas, como por ejemplo, legislar por encima del derecho positivo pero no en contra de la religión, de la monarquía misma, y del derecho natural, punto - éste último - crucial para nuestro tema, como veremos. Sin ir más lejos en una materia de tal envergadura, nos parece útil señalar que aquel universo cultural que a lo largo de los siglos crecióalrededor dela persona del rey (yno dela institución) tuvo una dinámica propria para enfrentarse a su historia, una dinamica que se movía entre dos polos: el de la voluntad y el de la causa. El equilibrio entre los dos nunca fue estable o definitivo porque privilegiar a uno o alotromedíalaamplituddelpoderíoabsoluto.Entérminosmásconcretos: no cabe duda que los tratadistas que sostuvieron las tesis acerca de los límites de la voluntad del monarca defendieron el principio de la causa, como mayor defensa de los derechos adquiridos por cuerpos y/o almas de la república. Sin embargo, lo compartido entre todos fue siemprelaideaquevoluntadycausaeranloscomponentesesencialesy necesariosdelajusticiasoberanadepositadaenlapersonafísicadelrey.

Demaneraquela respuesta a nuestra pregunta esquela soberanía queen 1808seretrovertióa"los pueblos"fuelajusticia porquelavacatio regis no dividió los poderes, mientras que lo que se desarticuló fue la legalidaddelarelaciónentrevoluntadycausa porquesólolapersonadel monarca - por ser el juez supremo - las podía vincular entre sí en una única decisión. Así que junto a la persona del rey se perdió aquella potestad que nosotros llamamos"moderadora"y que en aquel entonces sedecíaconmásacierto prudenteporserconsiderada desdesiemprela virtud más valiosa de los príncipes, incluso por los voceros borbónicos. Proclamar la "soberanía de los pueblos" no fue mucho decir, o mejor dicho, fue identificar porjusta causa (el cautiverioy nola abdicación) la soberanía del rey-juez en los "pueblos de almas" de la gran república hispano-cristiana, una fórmula con muchas incógnitas crucialesymuy concretas, empezando justamente por donde se ubicaba ahora la voluntadfrentealacausa.Puestoquenadiepodíalegitímamentetenerla una y la otra, desde el primer momento se generó una fractura entre las dos, en el sentido que los derechos adquiridos en el tiempo por los pueblos como cuerpos se volvieron la causa prima de la lucha política, mientras que la ubicación de la voluntad en las juntas y luego en 
las primeras asambleas tuvo una legitimidad frágil, y más en América que en la península. Estas afirmaciones necesitan ser aclaradas para evitar que se queden en un improbable limbo de abstracciones. Al revés, nuestro énfasis sobre la"retroversión" de la soberanía-justicia, sin divisionesdelos poderes, tienesu primera raison d'êtreen la necesidad de explicar su éxito concretísimo no sólo en los "medios ilustrados" sino también en otros medios que no tenían que ser "ilustrados" para conocer perfectamente lo que era la soberanía-justicia del rey. Si se acepta esta lectura de la crisis, entonces sus implicaciones no son de poca monta. En primer lugar, la crisis de la monarquía no impulsó aquel"potente" proceso de abstracción que la división de los poderes hizo posibleen otras revoluciones. La soberanía-justicia setrasladó de unapersonaamuchassinlaintermediación delanuevarepresentación política. En segundolugar, cualquier revolución es también un proceso de redistribución de recursos políticos entreactores viejos ynuevos que luchan entre sí para repartirlos, monopolizarlos etc. En nuestro caso el primer y fundamental recurso que la crisis redistribuyó en el intento de salvar la legalidad monárquica fue lajusticia, y no hace falta recordar que no se trataba de un "tercer poder", sino de el poder, es decir deaquel conjunto de potestadesque desde siglos habían garantizado el mantenimiento del orden social y político resolviendo conflictos entre esferas de intereses diversos que atendían a los derechos y deberes constituidos. Negar que la "retroversión" de un dispositivo de esta dimensión fue una ruptura sería negar la realidad. Tampoco se puede minimizar que en este enorme proceso sin precedentes circularon conceptos así dichos "modernos". El punto es que nosotros los historiadores no podemos producir juicios de valor por encima de losactores, tenemosquesaberenestecasocómoseleyóel nuevovocabulario, cómofueseleccionado,cómofuerelacionadoconel existente, porque es un dato que la palabra nueva no abrogó la vieja y que las dos convivieron en formas no conflictivas. Por ejemplo: en nuestras largasinvestigacionesnohemosencontradounasoladisputadoctrinaria entre unos supuestos defensores de la"soberanía de los pueblos"y unos de la"soberanía del pueblo", Quizás la hubo, pero nunca pesó en los acontecimientos políticos. Podemostambién afirmarque hasta en 
las numerosas cartas del primer constitucionalismo americanolos dos conceptos convivieron tranquilamente.

En tercer lugar queremos señalar que la redistribución de la soberanía-justicia entre los cuerpos de la república fue una ruptura histórica porque amplió abruptamente la arena política a un sinnúmero deactoresnuevos, precisamentelospueblos. Reconocerleaestoscuerpos el "depósito" de la soberanía significó otorgarle la potestad legítima de identificarsefrentealos poderes viejos (las audiencias) ynuevos (lasjuntas),yredefinirsefrentealosdemáspueblosprecisamentecomo sujetos políticos legítimos e "independientes" el uno del otro, fuera cual fuera su precedente ubicación en el gran cuerpo de la monarquía.Decirqueaquellatan proclamadaindependenciafueunamuestra de "autonomismo" corre el serio riesgo de minimizar el drama de la ilegal(ytraicionera)abdicacióny susconsecuencias, porqueeltérmino no corresponde a la época y no considera el problema de la soberanía. No acaso la ruptura con España, cuando fue planteada, se definió "independencia absoluta", como bien se sabe. Donde hay autonomía hay soberanía porque la primera puede darse sólo como parte de la segunda.Esoportunorescatarundato para nadasecundario:todaslas juntas pidieron el "reconocimiento" de las demás, es cierto, pero ¿por quérecurrieron al derecho de gentes? ¿Hasta dóndellegó entonces la vacatioregis? Elrecursoaljusgentiumsugierequelaausenciailegaldela personafísicadelmonarcaquebrótodaslasinstituciones delgobierno del rey porque, a pesar de la ficción del "deseado cautivo", no fue posible resolverlacuestión centralísima delasucesión`. Lafórmuladel "depósito de la soberanía" resultó ser inoperante. Es que los pueblos no podían suceder a su propio rey ni tampoco las juntas ni tampoco una supuesta regencia autonombrada, en realidad no para suceder al monarca sino a una junta central ingobernable, ni en fin las mismas

\footnotetext{
9 Alpocotiempo deescribirestas notas recibimos porcortesía del autorBOTANA, Natalio R. Repúblicas ymonarquías.Laencrucijadadelaindependencia.BuenosAires:Edhasa,2016.Trasunaprimerayrápida lectura nos parece que se trata de una obra fundacional del tema, hasta ahora no muy explorado. Lamentamos que el tiempo no permitió incorporarla como merece a nuestras reflexiones.
} 
Cortes de Cádiz que sí hicieron el gran salto a una monarquía constitucional pero sin alterar en lo más mínimo la justicia, como aclaró en su famoso discurso Argüelles. Repárese en la "prudencia" clásica de esta decisión de las Cortes: cambiar nada menos que la forma de gobierno de la monarquía y no tocar la justicia con base en la convicción "de que reformas de esta trascendencia han de ser el fruto de la meditación, del examen más prolijo y detenido, único medio de preparar la opinión pública para que reciba sin violencia las grandes innovaciones"10. Según nos dice un liberal de la talla de Argüelles, tocar la justicia era algo "trascendente" y con riesgo de "violencia", una reforma más difícil y compleja que la de implementar un gobierno constitucional. ¿Cómo explicar esta"prudencia”? ¿Por qué en opinión de las Cortes cambiar la justicia podía ser una aventura tan dramática? ¿Y cómo debemos pensarentoncesla nueva"división delos poderes"?

La "prudencia" acerca de la justicia no fue sólo de las Cortes gaditanas, laencontramosentodoelprimerconstitucionalismoamericano prey post-independentista; ésta es la razón que justifica nuestra radical atención al tema. Ninguna de las nuevas cartas en ningún espacio americano tocó la justicia. Más adelante vamos a recuperar la cuestión, aquí nos interesa enfatizar un punto: los resultados de cualquier reconstrucción histórica de las luchas y de la competición política en esta época tan dramática van a depender de cómo se mira este trascendental tema. Si pensamos que la justicia fue desde el primer momento un "tercer poder" por efecto de la "retroversión", entonces nuestros análisis se adaptarán a las logicas del patrón dominante de las revoluciones atlánticas. Si estamos convencidos que la justicia no se dividió en tres poderes, entonces tenemos que construir un patrón distinto pararecuperara nuestro entendimientola especificidad delas revoluciones hispánicas. No hay que olvidar que en el caso francés la cuestión de la reforma de la justicia se debatió intensamente a lolargo

10 Discurso preliminar leído en las Cortes al presentar la Comisión de Constitución el proeyecto de ella, en Constitución política de la Monarquía Española, promulgada en Cádiz a 19 de marzo 1812, ed. facs. Cádiz, 2000. 
de todo el proceso ${ }^{11}$, y es cierto que el código civil se logró gracias a Napoleón y no antes, pero es también cierto que uno de los primeros decretos de la Convención prohibió a los jueces tratar"asuntos de gobierno", y no fue una decisión secundaria ${ }^{12}$. La evaluación de aquel décreto depende de la idea que se tiene acerca de la naturaleza del podery de la política en aquellos tiempos, y se trata de un asunto nada obvio. No es lo mismo decirque las monarquías absolutas sefundaron sobre el "gobierno de los jueces", o que se fundaron sobre el gobierno de unos "funcionarios"13. En este segundo caso, sin embargo, resulta difícil explicar el décreto de la asamblea francesa y la aclaración de Argüelles en Cádiz.

En el orbe hispánico quebrado no tocar la justicia significó por lo tantonoponerendiscusiónlanaturalezadel poderpolítico,yessólouna paradoja aparente que esta opción a primera vista "conservadora" constituyó una ruptura irreversible. Nadie mejor que la Junta de Sevilla definió en 1809 la situación provocada por la retroversion:"conviene igualmente no perder de vista un fenómeno político en que pocos habrán reparado, esto es, que aunque la constitución de España es en sí y debe ser en adelante monárquica, la forma actual del gobierno esabsolutamenterepublicana.Juntasprovincialescreadasporunpueblo reducido a la orfandad, y otra suprema emanada de aquella, reú-

11 Véase BART, Jean; HALPÉRIN, Jean-Louis, L'impossible Code civil, 1992. Prefacio de Pierre Chaunu. Droit et Société, $n^{\circ} 22,1992$. Transformations de l'État et changements juridiques: l'exemple de I'Amérique Latine. p. 690-695. (Coll. Histoires).

12 Acerca de la falta de una separación entre justicia y administración antes de 1789 en Francia, véase MANNORI, Luca. Per una "preistoria" della funzione amministrativa - Cultura giuridica e attività dei pubblici apparati nell'età del tardo diritto comune. Quaderni fiorentini per la storia del pensiero giuridico moderno, vol.42, n 1,2013.p. 201-279. ISSN 0392-1867; Idem. Centralization et fonction publique dans la penseé de l'Ancien Régime: justice, police et administración. In: PERTUÉ, Michel (ed.). L'administration territorial de la France (1750-1940) Orléans: Presses Universitaires d'Orléans, 1998, p. 247-257. La ruptura entre administración y justicia ha sido enfatizada en la obradeBIGOIT,Gregoire.Introductionhistoriqueaudroitadministratiffrançaisdepuis 1789.Paris:Droit Fondamental, 2002.

13 Empleamos el término "gobierno de los jueces" en el sentido formulado por MANNORI, Luca, Op. Cit., 2013, p. 201-279. Por otra parte hay que recordar que el término "funcionario" fue inventado no acaso en la Francia del primer Imperio. 
nen legitimamente toda la representación, autoridad y poder. En una palabra forman una república que tiene en deposito la monarquía"14. La declaración es anterior a la disolución de la Suprema y la imagen deungobiernodejuntasestructuradoverticalmenteexpresalanotoria posición conservadora de Sevilla que quiso excluir América. Sin embargo, la idea de una "república que tiene en depósito la monarquía" es algo distinto, aclara con singular lucidez la histórica ruptura desencadenada por la ilegitimidad de Bayona. El intento de ocultar la profundidad de la crisis relatando un supuesto"cautiverio"y un supuesto "depósito" no fue suficiente para limitar la lógica de los eventos, tan es así que en la Península se convocaron las Cortesy en América estalló el conflictoalrededordelaindependencia-autogobierno.Loquecuenta aquí es señalar un punto crucial: el "poderío absoluto" de la persona física del monarca no era reversible so pena de perderse en el camino, ¿cómo hubiera podido la nueva república conservar lo esencial de la soberanía, aquella relación indisoluble (aunque inconfundible) entre "voluntad" y "causa" que durante los siglos había garantizado el "justo" gobierno de los reyes? No tocar la justicia proclamando a la vez la división de los poderes - en España y en América - fue una atrevida apuesta ilustrada de todos los actores del Atlántico hispano, densa de incógnitas para el futuro. ¿Porque llamamos a la mesa la llustración? La razón es que el así dicho "reformismo ilustrado" en el orbe hispánico, pero también en el europeo continental, tuvo siempre un límite inquiebrantable: reformar sí, pero con la cooperación de la sanior pars de la sociedad, reformar pero no destruir, cambiar las relaciones entre ciertos poderes pero no su naturaleza. En Francia los eventos quebraron esta frontera generando un fantasma amenazante para todo el orbe hispánico que brotó de nuevo en 1808 con Napoleón, así que aquella frontera de la monarquía borbónica se reprodujo en la nueva república de "los pueblos" con el notorio consenso de ellos. Decir que la república juntista fue una república ilustrada, hija de los proyectos

${ }^{14}$ Citado en ARTOLA, Miguel. Los orígenes de la España contemporánea. Madrid:Centro de estudios constitucionales, 1999 , vol. $2^{\circ}$, p. 325. 
borbónicos en todas sus declinaciones yen todas sus potencialidades, es llamar la atención sobre el gran tema de la llustración americana, quesífue un"archipiélago"peromuchomás extendido de sus tertulias y de sus gacetas si sólo miramos lo que se pensó y escribió a partir de 1808 en materias politico-institucionales ${ }^{15}$. Fue aquella (de la república) una ilustración bien anclada en el siglo XVIII hispano y bien consciente de sus fronteras históricas.

Dos temas entre los tantos. El primero es la "orfandad", la narración del nacimiento de la república, hija legítima del pater ausente, un paradigma que fue desde el primer momento dominante yque no hubiera podido ser tan exitoso sin el precedente borbónico. El “paternalismo" de la nueva dinastía sí fue un dispositivo creado para el monarca y su"gobierno de los jueces", perola vacatio lo rebotó en contra de ellos según una dinámica totalmente endógena ${ }^{16}$. A pesar de la disputa dieciochesca en contra de la tradición romanista, el Pater borbónico tuvo en ella su raíz porque el dispositivo se adaptaba muy bien a la nueva extensión del poderíoabsolutoy de sus nuevos recursos, las jurisdiccionesretenidas, losprocedimientosreservados, lasnuevasvisitasylastbutnotleastlaNueva Plantaquequisoliquidarlo"compuesto" de la monarquía. Repárese entonces en algunos elementos cruciales del nuevo dispositivo:el Pater romano tenía la potestas pero para ejer-

15 La imagen eficaz del "archipiélago" en SILVA, Renan. Los ilustrados de Nueva Granada 1760-1808. Genealogía de una comunidad de interpretación. Bogotá: Universidade Eafit, 2002.

16 Es muy llamativa sobre ese punto la posición del cabildo de Nueva España en 1808, poco antes del golpe de la Audiencia en contra del virrey Iturrigaray: "hay sólo dos autoridades, la del rey y la de los cabildos, la primera puede faltar y de consiguiente falta en los que le han recibido como una fuente que emana por canales diversas, la segunda es indefectible por ser inmortal el pueblo". Dos puntos merecen atención: sin, el rey, sus representantes - los jueces - no tienen legitimidad, y la imagen de la fuente es de las más clásicas, la encontramos en la obra de Baldo degli Ubaldi (1327-1400). Por otra parte, la "inmortalidad del pueblo" es un concepto teológico también de antigua tradición (Isidoro de Sevilla) y nos muestra que "pueblo"y "pueblos" convivían perfectamente por identificar un sujeto moral cristiano obviamente en singulary unos sujetos corporativos obviamente plurales. La relación entre los dos conceptos es análoga a la que une "república"y repúblicas". El texto de 1808 citado (el destacado es nuestro) en GENARO, García. Documentos históricos mexicanos. Obra conmemorativa del primer Centenario de la Independencia de México. México: Museo Nacional de Arqueología, Historia y Etnología, 1910-12, t. II, p. 148. 
cerla necesitaba de la auctoritas, es decir de la fuerza legítima para dar eficacia a sus decisiones, algo que compartía con las magistraduras políticas. Sin embargo, la esfera del Pater era la justicia y no la ley, y la segunda no cruzaba la primera en la familia, es decir que la potestas paterna era autónoma de la norma positiva, era ab-soluta. Por último, cabe recordar que el Pater no era necesariamente el genitor. César ejemplo muy notorio - nombró en su testamento a Octaviano para la sucesión, un lejano pariente pero no de sangre Julia. Por supuesto, a largo de los siglos los límites de la Potestas paterna variaron, pero aquí recordamos algunos de sus elementos originarios sólo para matizar la naturaleza no ideológica sino"dispositiva" del paternalismo borbónico, que explica su dinámica cuando la gran familia del orbe hispánico se quedó precisamente "huerfana". Si el Pater borbónico fue un dispositivolegaly no una mera imagen retórica, también sus "huerfanos" no fueron una imagen sino un estatus "dispositivo" que permitió una auto-identificacióncomopersonaslegítimamenteemancipadas.Noesun caso entonces ni (otra vez) una retórica que a partir de 1808 se impuso a lo largo y a lo ancho del imperio el término "emancipación" junto con su sinónimo "independencia", y que las luchas políticas se dieran al interior de este gran espacio semántico. Es interesante anotar que cuando llega la "independencia absoluta", las declaraciones americanas en muchos casos cambian de género y se refieren a la "madre" España. La atención a las dinámicas del "paternalismo" borbónico no quiere en absoluto minimizar el peso de lo "nuevo" atlántico sino plantear la necesidad de un mayor equilibrio entre los dos. Hasta una prueba contraria, los dos se cruzaron en múltiples formas y sin entrar en conflicto abierto, lo cual precisamente se puede explicar sólo si se acepta que el idioma borbónico no desapareció en 1808. No hubo tampoco una contraposición entre lo "borbónico" y lo "hasbúrgico" ni una supuesta"regeneración"del segundo a expensas del primero", al revés: toda la narrativa de la crisis logró legitimarse precisamente

17 La tesis acerca de lo"hasbúrgico" por efecto de 1808 fue planteada por GUERRA, François-Xavier. Independencia y modernidad. Madrid: Mapre, 1994. 
porque radicalizó la lógica "dispositiva" del Pater ilustrado, una lógica - este es el punto - potencialmente muy conflictiva. Antes de la desaparición culpable del Pater, los “hijos"competían fisiológicamente para ganar un estatus mejor, un fenómeno que no desaparació en 1808, mas bien se incrementó en formas nuevas. La república de la "soberanía de los pueblos" fue altamente conflictiva, pero el drama que se consumó entre 1808 y los años de las independencias "absolutas"se desarolló según patrones bien anclados en la legalidad monárquica, empezando por la justicia y el derecho vigente que - valga la reiteración - nunca fueron puestos en discusión. Se les fueagregando sin duda muchas novedades, empezando por las constituciones, pero hemos ya aclarado lo que pasó en Cadiz y en América.

La "nueva" historiografía, la que se hace cargo del gran cambio que significó superar el clásico paradigma de unas independencias protagonizadas por "naciones" preexistentes, y que ahora está convencida que éstas no fueron la causa sino el efecto de la quiebra de la monarquía católica, tiene que medirse con una cuestión central: ¿cómo se releyó lo “antiguo” y cómo se leyó lo "nuevo”? Hasta ahora se hicieron grandes avances sobre cómo circularon los conceptos, y con mucha más atención a los "nuevos" que a los "viejos", sin embargo la naturaleza de los dos depende de la lectura de los actores porque - como dijo incansablemente Umberto Eco - un lector es un autor, máximeen nuestrocasosiestelectoractúa leyendoytoma decisiones. Estas cuestiones tienen mucho que ver con la llustración hispánica. Nuestro segundo tema a este proposito se origina en la Salamanca de 1813 trás la publicación de la carta gaditana, cuando el encargado de dictar cátedra de Derecho pidió a la Junta de Derecho de la universidad el modo de abordar el estudio del Derecho y Constitución. La Junta tomo una decisión sugestiva: propuso seguir el metodo clásico de las concordatio (concordancia) de modo que, como antaño se hizo paraintegrareljuspropriumaljuscomune, ahorapartiendodeltextode la carta se fue señalando a los alumnos las leyes de la Novísima Re- 
copilación correspondientes a cada articulo ${ }^{18}$. Se podría argumentar que la de Salamanca fue una decisión "conservadora" pero sería una evaluación algo atrevida, que supondría la existencia de dos modos de leer la indudable novedad constitucional, lo cual hasta ahora no es cierto. Las diferencias políticas no necesariamente salieron de diferencias de lectura y no pocos datos sugieren que fue así. Recordamos que a partir de la reforma de Campomanes de 1771 los programas salmantinosfueron extendidos alos colegiosamericanosyquela decisión de 1813 seenmarcó en aquellatendenciadelasnuevasacademias jurídicas impulsadas por los gremios de abogadosy juristas en pos del "humanismo jurídico", que buscó "simplificar"la lectura del gran universo del Derecho hispánico con el recurso a unas primeras formas de racionalización. Fue algo importante, sin duda en línea con la tendencias europeas deaquellas décadas que experimentaron en la Prusia de Federico Il y en la Toscana del granduque Leopoldo la implementación delos primeros códigos penales, retirados sin embargo después de pocos años, una muestra - ya lo hemos señalado - del difícil camino de la llustración por afuera de salones y gacetas. En la península hispánica las nuevas formas de sociabilidad jurídicas plantearon la necesidad de un Derecho más "racional"y hasta de unos códigos, pero no pusieronendiscusiónelmétododeladisputatioydelaconcordatiocomo su complemento indispensable. Hubo dos potentes razones: la rica y controvertida busqueda dieciochesca de una"ley fundamental" de la monarquía no tuvo éxito a pesar de la Nueva Planta ${ }^{19}$. Se hizo evidente que uniformar el Derecho era mucho más difícil que reformar el gobierno del rey,comosedieron cuentalosgaditanos. Por otra parte,esta insuperablefronteramantuvoen plenavigencialalógicacasuísticadel sistema de gobierno y es llamativo el hecho que este "espíritu de las leyes"hispániconofuenuncaimpugnadoporlos reformistasniporlos

18 Véase ROMERO, Alonso. La formación de los juristas. In: GARRIGA, Carlos (coord.) Historia y constitución.Trayectos del constitucionalismohispánico.México:Centro deinvestigacióny docencia económicas, 2010. p. 107-137.

19 Véase (entre tantas) la obra VALDES, Jose Maria Portillo. Revolución de nación. Origenes de la cultura constitucional de España. Madrid: Boletín Oficial del Estado, 2001. 
revolucionarios en las dos orillas del Atlántico. El mundo del Derecho queregíala república de repúblicas, conel reyantesy sinel rey después de 1808, siguió representándose a todos los "pueblos"- sin soberanía y con soberanía - como un conjunto cumulativo de normas y dispositivos legales de distinta naturaleza, y todas en principio válidas por ausenciadederogaciónprevia.Noessorprendenteentoncesquejunto alcasuismosiguióvigentesumétodohermenéutico,ladisputatio-correlatioquedesdesiempretratabadesolucionarcadacasoconsoluciones probablesoverosímilescuyasargumentacionesfueronsiempresacadasdel mismo universo jurídico, exactamente como se decidió en Salamanca acerca de la carta gaditana. En fin, el método de lectura siguió fundándosenosobreaxiomassegurossinosobreopinionesprobables.

\section{Leer la ley y la constitución}

La cuestión de la lectura de lo"nuevo"adquiere entonces una centralidad crucial si queremos reconstruir las formas de la competición política, máxime porque en lo"nuevo" hay que incluir en primer lugar la vacatio regis y no lo que vino de Francia o del Norte, puesto que la lectura de la crisis generó las "otras" lecturas y no al revés. No solo fue nueva la ilegal ausencia de la persona física del monarca sino que lo fue aún más la soberanía una vez retrovertida a los "pueblos". Nuestra reiteración acerca de su fisicidad única antes de 1808 quiere señalar la imposibilidad de su retroversión íntegra en la república“huerfana"por la disociación que se dió entre la ubicación de la voluntady de la causa. Aquí encontramos lo "nuevo" más profundo: la causa en el pasado pudo siempre ser presentada por el rey o por una "persona", cuerpo o individuo, y en 1808 quedó claramente en manos de los "pueblos" porque siempre había sido un derecho garantizado por la justicia del monarca, pero ¿dónde se ubicaba ahora la voluntad? ¿Quién podía hablar y decidir en nombre del"deseado"? Este fue el dilema que marcó el camino de la crisis y que fue heredado por las nuevas repúblicas independientes. Sin la persona del rey no hubo posibilidad de dividir los poderes ni cambiar por esta vía la naturaleza de la soberanía, pero, sí, se dió una división en la soberanía misma y fue otra gran ruptura 
histórica. Ni la pacificadora teoría del "depósito" sobrevivió a este dilema que marcó el camino de la gran crisis y el de las repúblicas independientes. Claro que hubo intentos de ubicar la voluntad en los nuevos cuerpos representativos, juntas y asambleas, pero su legitimidad nunca logró consolidarse en forma irreversible, nunca fue realmente fundadora de símisma porque siempre pudo ser cuestionada por una o mas causas lanzadas como recurso en la contienda política.

El dato más aclarecedor son los nudos de la representación política. Más allá de las luchas que hicieron correr sangre, todos los actores compartieronel principiodel mandatoimperativo,ynisabemosalmomento cuándo realmente se superó este vínculo en el siglo republicano. Las instrucciones que los cuerpos territoriales - pueblos y cabildos - enviaron a sus representantes en las asambleas antes y después de lasindependencias, muestrancuántolavoluntaddelosrepresentantes estuvo siempre limitada por las causas de los representados. No cabe duda que las asambleas fueron una gran novedad "republicana" desde el primer momento, al igual que las elecciones, pero la naturaleza del mandato no cambió. La practica de las instrucciones definió así la problematica frontera entre la "soberanía de los pueblos" y la del "pueblo", una frontera nunca cuestionada en sus fundamentos pero potencialmentemuyconflictivapolíticamenteporladobleimputación que expresaba. El tema se vuelve aún más intrincado cuando miramos alpoderconstituyente;elcasomásestudiado,eldeCádiz ${ }^{20}$, muestraalgo compartido por las demás experiencias: a las instrucciones se añadieron las continúas peticiones que llenaron los trabajos de la comisión, de manera que los artículos de la carta expresaron también una actividadjurisprudencial de las Cortes con baseen la permanencia de lajusticia monárquica y de su orden casuista. La pregunta en este punto es

20 La bibliografía es muy extensa, recordamos aquí la conocida obra de LORENTE, Marta; GARRIGA, Carlos. La constitución jurisdiccional. Madrid:Centrol político y constitucionales, 2007. En ella se enfatiza el papel crucial del principio de responsabilidad, una referencia que hemos utilizado en las páginas que siguen. Una actualización de la carta gaditana en LORENTE, Marta; VALDES, José Maria Portillo (dir.). La Constitución en el orbe hispánico (1808-1826). Madrid:Congreso de los Diputados, 2011. 
si un poder constituyente puede coexistir con el mandato imperativo. Siéyès diría que no y reivindicaría la decisión de la Asamblea que en 1791 - en plena redacción de la constitución - que no quiso tomar en cuenta las más de cuatro mil peticiones acumuladas en sus oficinas ${ }^{21}$. Sin embargo, hay que recordar otra vez que las revoluciones liberales europeas,enlospaísesdondesedieron,seoriginarondecartasoctroyeés porlosmonarcasynodecartas producidas porasambleasconstituyentes soberanas. Más allá de los caminos dramáticos que de Siéyès hasta Schmidt marcaron el debate teórico acerca del poder constituyente, lo que cuenta aquí es registrar que históricamente la cuestión se puso siempre en una "situación repúblicana" o potencialmente tal. La del orbe hispánico fue precoz, en el sentido que se dió cuando no había ni en Francia ni en Estados Unidos una doctrina coherente y segura acerca de la naturaleza de este poder tan crucial y a la vez tan “improbable"en susfundamentos.La naturaleza del constituyenteamericanofue definida por la crisis de la monarquía como en Francia y no por la del imperio como en las colonias del Norte, pero a diferencia de Francia el poderconstituido (el rey) no existía en 1808 , no era el enemigo político a quien debía expropriarsela soberanía para compartir los poderes. La soberanía recayó en los "pueblos"antes que se pudiera montar la ficción del "pueblo soberano", y no se trata de una mera cronología de los eventossino de una situación vinculante: ¿eraimaginable expropriara los"pueblos"? ¿Definirlosel enemigohistórico delaslibertadeso delas repúblicas? ¿Con que legitímidad y con qué sentido? Cualquier intentodecontestaraestosdilemashubierasignificadonegarsencillamente la realidad.

Todo lo que a primera vista parece "tradicional" - como algo ineluctable que se resiste al cambio - fue en realidad producto de los vínculos de necesidad creados por la crisis de la monarquía y por lo tanto tan "nuevo" como lo que vino de afuera del orbe hispánico. Aquí el

${ }^{21}$ Vease MANNONI, Stefano. Une et indivisible. Storia dell'accentramento amministrativo in Francia. Vol. II : Dalla contestazione al consolidamento. Milano: Per la storia pensiero giuridico moderno, 1996. p. 245. 
gran tema de las lecturas que se dieron de las "novedades" cobra su densidad. Por cierto, las Siete Partidas habían autorizado juntas de notablesencasodevacatiolegis,cuandopornecesidadyurgenciaunos casos nuevos necesitaban de una solución normativa a nivel local que el monarca ratificaba en un segundo momento. En la Nueva España del siglo XVI hubo por ejemplo muchas juntas de ciudades - cada una con su apoderado - que trataron las cuestiones más urgentes de la colonización. Sin embargo, 1808 otorgó al juntismo una naturaleza inédita y necesitó de lecturas acordes a la"retroversión"y sus dilemas. Uno es el significado en aquel contexto del concepto de "soberanía del pueblo": mucha historiografía está convencida que la expresión fue nueva y deudora de las revoluciones atlánticas. Puede ser, pero no es tan evidente como parece. El mismo término se encuentra en la tratadística hispánica de los siglos hasbúrgicos y no es difícil rastrear sus raíces en el tomismo:"pueblo" como populus cristiano organizado en comunidades parroquiales, anteriores a la monarquía misma, pero al mismo tiempo"pueblo" como comunitas jerárquica que se identifica con sus autoridades constituidas, como fue declarado por la junta mexicana de 1808 y boliviana de 1810. No estamos en absoluto proponiendo una nueva versión conservadora o "tradicionalista" de la historia, como se hizo en el pasado, lo que nos interesa es llamar la atención sobre un dato:la continuidad delorden legal dela monarquía en quiebra tuvo un papel protagónico en las lecturas de los cambios que se estaban dando, lo cual no implica de por sí un rechazo de lo "nuevo"atlántico. El método de la concordatio aplicado al tema de los pueblos/pueblo propone otro dato: el "pueblo" como autoridad constituida podía identificar la autoridad de un municipio, de una junta, y de una asamblea, de manera que la lucha entre soberanías no fue originadaexclusivamenteporproyectospolíticosdiferentes, sinotambién porlacompetenciaentrejurisdiccionesquelavacatioregis"emancipó" las unas delas otras. Porque no cabe duda que estas luchas jurisdiccionalesidentificaron actores, lógicas, y recursos políticos cruciales en los procesos que dibujaron el camino hacia las independencias.

Cambiar las formas de gobierno sin tocar la justicia soberana, luchary competir con recursos otorgados por la legalidad fue una carac- 
terística constante de las décadas revolucionarias, algo-valga la reiteración-quenominimizalas rupturas que se dieron sino quelas explica en todos sus alcances, empezando por la amplitud de las movilizaciones políticas. Lo que se dió a lo largo de la "situación republicana" fue ungigantesco proceso deredefinición deinstituciones existentesque interactuóconlasnuevasinstitucionesyconlasnuevasconstituciones. ¿Cómo? A partir de una decisión que fue común a todas las opciones políticas: el mantenimiento de las "leyes vigentes", es decir del orden legal en todas sus formas y lecturas. Todas las cartas reafirmaron este principio que tuvo consecuencias definitivas en la fisiología de la competición política. Un ejemplo: un artículo igualmente reiterado en el primer constitucionalismo americano, hasta bien entrada la época republicana, instauró el principio de la"obligación"de los nuevos ciudadanosa"defender"las constituciones, mientras otroartículotrasladóa las cartas el antiguo principio de la responsabilidad de los"empleados públicos", término que incorporó siemprea todaslas personascon cargo de jurisdicción de cualquier nivel en lo cívil y en lo eclesiástico. Una nota: la responsabilidad de los "empleados" siguió siendo por su persona y su patrimonio y no por sus actos. ¿Cómo se pudo entonces leer el campo de lo"inconstitucional"? ¿Con base en qué orden de referencias que permitían identificar una transgresión dela carta? La respuesta es bastante ineludible: la constitución se leía con los procedimientos del orden legal existente, casuista, "concordante" o "discordante" que fuera, es decir que las cartas reconocieron el derecho a múltiples lecturas de si mismas por parte de cualquier ciudadano. Quizás no sea atrevido pensar que estos dispositivos dieron un formato legal a la competición política poniéndola al alcance de todos los ciudadanos, y en una arena que la "retroversión" amplió en forma inimaginable.

Encontramos por esta vía una especificidad americana de hondo calado. La historiografía del "Derecho indiano" ha enfatizado - y desde hace décadas - que el jus commune fue el gran articulador del orden colonial. No sólo porque en América no hubo una feodalité trás la liquidación en el siglo XVI de las jurisdicciones encomenderas, sino porque a las Indias nolefueron reconocidasun derechoforal proprio, a pesar de la narrativa criolla y también indígena. Al incorporar la lega- 
lidad pre-revolucionaria las cartas constitucionalizaron la vigencia del juscommuneconsucargahistórica de"costumbres"localesquela"eclosión" municipalista transformó en jurisdicciones de autogobierno. La cantidad denuevos municipios impulsados por el constitucionalismo fue asombrosa, sea en las áreas "gaditanas" sea en las "insurgentes" con excepción de Argentina, en particular lo fue en los territorios indígenasandinosymesoamericanos,yentodoselloslosalcaldeselectivos mantuvieron lasfacultadesjurisdiccionales de laépoca borbónica.No tenemostodavíauncálculocompletodelas nuevasjurisdiccionesmunicipales, pero nocabedudaquela extensión demográficay territorial del fenómeno debilitó los espacios urbanos en favor de los rurales. La ruralizacióndelopolíticofueuntrascendental procesoquemoldeólahistoria social del siglo XIX, otorgando a las luchas agrarias un contexto institucional inimaginable en la época colonial. La inclusión de nuevos actores sociales en la arena política constituye un campo de estudiosquesobrepasa los límites delos derechosotorgados porlascartas. Un ejemplo es la socialización de la guerra: aunque - como dijimos - nuestrasinvestigacionesestántodavíaenmarcha,loqueconocemos hasta ahora de México, Perú, Nueva Granada, y Alto Perú muestran comola extensión de los fueros del ejército y sobre todo de las milicias incorporóelmundodelosvecinosprincipales delospueblosalaluchay competición política. El mismo caudillismo nació en este contexto de redistribución de recursos legales: el caudillo sin duda tenía capacidad de liderazgo perosiemprefue el juez privilegiado de sus hombres, de sus patrimonios, y de sus relacciones laborales, y su llamado a los "pueblos" - y nunca al "pueblo" (sic) - para tener legitimidad y movilización tuvo queapoyarseen la consulta alospueblos en lasformas de un cabildo abierto o de una asamblea de vecinos. Lo que cuenta esque estas formas de sociabilidad de antes, renovadas en sus dinámicas y ensusobjetivos, exigieronsiempreunosprocedimientosmuyformales por ser una causa, empezando por un acta "perfeccionada" (así se decía): la declaración del "común" en pro o en contra de un plan político tenía que ser promulgada por un juez local, o por un alcalde, o por un notario, o por un cura, o por un "vecino principal", al igual que una representación o una queja. Las fuentes de archivos son inagotables y 
confirman que la competición política no armada tuvo una capacidad demovilización porque siguió la víajudicial. Lo revolucionario fueque los sujetos libres de praticar sin límites estos procedimientos fueron ahora todos los cuerpos de la república, que gracias a las cartas tuvieron el derecho de leerla, interpretarla y defenderla.

Llegamos así a otro punto crucial de nuestro tema: las diferentes relaciones entre ley y constitución, un tema en primer lugar histórico porque sería central en el dilema entre "civilización y barbarie"y en su tormentosanarrativaacercadelanueva polis.Tampocoel temaesnuevo en la historiografía y de momento se queda abierto. Sin pretensión de resolver la cuestión, nos interesa replantearla a partir de unas fuentes a primera vista absolutamente marginales y eruditas, los llamados "prontuarios de abogados", un género de literatura jurídica florecido entre la segunda mitad del siglo XVIII y las últimas décadas del XIX en toda Hispanoamérica, fácil de ubicar en sus bibliotecas nacionales. Juristasyabogados escribieronestasobras parafacilitar precisamente las lecturas y los caminos en el universo del derecho existente, un tipo de escritura típicamente ilustrada que nos muestra alcances y límites del "racionalismo jurídico" hispánico y americano. Se escribió para facilitar la "práctica" de la ley, término que significaba "conocimiento" de cómo pensar los casos en las causas de cualquier tipo. Por su naturaleza los prontuarios nos proporcionan una información significativa para empezar a contestar a una pregunta: ¿el concepto de ley cambió en el siglo republicano? Como se sabe el tema del "incumplimiento" dela leyesfue angustioso a pesar de que lo fue también en la época colonial.Los prontuarios señalan constantementeyen todoslos países la necesidad decorrelaccionarlasantiguasleyesal nuevo contextorepublicano con sus constituciones. En segundo lugar, la reproducción de laconcordatio paraleerlonuevo sin perderloantiguonosmuestraque lainterpretacióndelaleyydelasconstitucionessiguióvinculadaensus múltiplesexpresionescasuistasaloscriterios hermenéuticosproprios 
deljus communeyen las manos de un sinnúmero deactores sociales ${ }^{22}$. Una rápida comparación nos ayuda quizás a medir historicamente la cuestión. En el así dicho"estado de derecho"que se fue construyendo en otras áreas - y que sólo a posteriori aparece relativamente sencillo a pesar de que nunca lo fue - el "legocentrismo" se fundó sobre el principiodelaautosuficienciadelaleygarantizadoinstitucionalmente por unos códigos, por un nuevo tipo dejuez, por nuevos procedimientos monopolizados por el "tercer poder"y por el legislador. Al orígen de este largo y difícil proceso se encuentra simbólicamente la tercera declaración francesa de los derechos de 1795, que al introducir por primera vez los "deberes"liquidó también el jusnaturalismo ilustrado del '89. En fin - como diría Bobbio - la autosuficiencia de la ley necesitó deljuspositivismoyno deljusnaturalismo ${ }^{23}$, máximesi este último era católico como en América. Las revoluciones fijaron entonces una

22 Se destaca la atención de la historiografía argentina que valorizó el estudio de estas fuentes en el marco del proyecto“Nuevos campos de investigación en la historia del derecho indiano: el derecho indiano provincial y local y la pervivencia de la cultura juridica indiana después de la emancipación iberoamericana", dirigido por Víctor Tao Anzoategui. Citamos aquí como ejemplo al artículo de ABASOLO, Ezequiel. Las "sanas doctrinas" del doctor Castro en los tiempos de la codificación. Pervivencia de la cultura juridica indiana en la segunda edición del Prontuario de Pratica Forense. Revista de historia del derecho, n³4, 2006, p. 13-30. ISSN 1853-1784. La primera edición de este prontuario salió en 1834 y la segunda en 1865. El artículo estudia la nueva edición de 1865 a cargo de José Domínguez, futuro presidente de la Corte Suprema Argentina (1872-1887). No sólo en los tribunales se consideró a Castro como uno de los escritores de "mayor aceptación" y uno de lo más "prácticos", sino que no pocas veces sus criterios inclinaron las decisiones de los magistrados por la importancia reconocida de su "metodo explicativo". Los comentarios de Domínguez, sí, agregaron al texto de 1834 la nueva legislación pero siempre como expresión de un concepto de ley cuyo entendimiento dependió de las tramas de argumentación y de los criterios del secular jus commune. Más el art. 124 de la constitución bonaerense de 1854 (11 de abril) estableció que las sentencias judiciales podían fundarse en el texto expreso de la ley como en "los principios o doctrinas de las materias". El texto del doctor Castro tuvo amplia circulación en Chile en los años 40, país donde se publicó en 1832 la Instrucción forense del modo y orden de substanciar la justicia, de Francisco Gutierrez de Escobar, un texto escrito medio siglo antes. Véase ARDANAZ, Daicy. Francisco Gutierrez de Estrada: sus bibliotecas y sus escritos. Revista de Historia del Derecho, n. 2, 1974, p. 175-190.

${ }^{23}$ Véase BOBBIO, Norberto. Giusnaturalismo e positivismo giuridico. Milano: Edizioni di Comunità, 1965. Quizás vale la pena hacer una breve referencia al problema Bentham (1748-1833), un autor de mucho éxito en la América revolucionaria, como es bien sabido. 
encrucijada atlántica crucial:por una parteel juspositivismo y por otra el jusnaturalismo constitucionalizado.

Es cierto que, al igual que en otras latitudes, las cartas americanas inventaron dispositivos de autotutela, sin embargo fijaron otros que podían quebrar la misma carta, como el ya citado principio de responsabilidad de los empleados públicos a partir de múltiples lecturas de los textos. En otras palabrasel derecho de hacerpolíticalegalmente se quedómuchomásamplioquelosderechospolíticosenunciadosenlas cartas. La lectura de las nuevas normas con base en la legalidad "vigente"y constitucionalizada sugiere que ni la ley ni las cartas lograron tener autosuficiencia propia por falta de dispositivos adecuados, los cuales podrían aclarar muchos aspectos acerca del "incumplimiento" delas normas. Elinterés por cómo sefueron dandolas relacionesentre leyyconstitución tiene unajustificación que sería equivocadolimitara unas cuestiones "técnicas", se trata más bien de encontrar una explicación razonable de las formas del conflicto político. Su "vía judicial" no fue por supuesto la única pero, sí, fue dominante por los recursos que ofreció y por la amplitud social de los actores potencialmente involucrados. Hemosapuntadoque los"perfeccionamentos"discursivosnecesitabandesujetosfamiliarizadosconlosprocedimientosdelderecho casuístico vigente para armar un expediente en forma debida, puesto que en aquel mundo juridico-político una causa era real y legítima fuera cualfuera su objetivo-sóloa partirde un expedientepresentado según las reglas. Sin expediente, es decir, sin causajurisprudencial, no había acción política legítima. Este dato tan complejo y a la vez tan sencillo abre un capitulo crucial de historia social: por supuesto no es posible pensar que cuerpos como los pueblos, tan lejanos del alfabetismoy perdidos en una geografía inalcanzable, pudieron redactar sus documentos políticos sin un sujeto escribiente e informado de las "cosas". De otra forma no se puede explicar - valga la reiteración la alta tasa de politización de los territorios americanos. Unas listas de pueblos con "escrituras" nos proporcionaría una primera imagen cuantitativa y geográfica para identificar a los "vecinos principales" que "entraron" en la competición política para quedarse en forma estable. De manera que el orden legal monarquico dejó a las repúblicas 
un fruto amargo: una competición política sin limites pero con reglas compartidas por todos los actores, un fruto que reprodujo con nuevo ropajeel dilema desiempre: ¿cómo moderarla república?Repáreseen el hecho que sevotó con bastanteregularidad a pesar delos conflictos armados y de la inestabilidad de los gobiernos. El voto no pacificó las luchas no sólo porque no debía ser competitivo en principio, sino - y mucho más - porque los actores que se podían movilizar por"vía judicial"fueron siempre más numerosos que los que tuvieron derecho de voto, o - como en Argentina - los dos se identificaron en uno por la amplitud precoz del sufragio.

Es también cierto que a lo largo del siglo republicano se dió un incremento espectacular de la legislación y se redactaron nuevos códigos, pero éste sólo dato no significa que cambiaron las formas de entender la ley. El mismo Andrés Bello en sus notas que sirvieron para redactar su conocido código no renunció al método jurisprudencial del pasado. Todo este campo de estudio no puede seguir fuera de la historiografía política porque el gran tema de sus relaciones con el constitucionalismo fue uno de los problemas del siglo XIX y no sólo en América. La frecuencia de los cambios constitucionales no es por lo tanto un sintoma de "fracasos" sino de la naturaleza del primer constitucionalismo y de sus relaciones con el orden legal. Aquí las definiciones son cruciales: ¿"continuidad", "pervivencia", "resistencia al" o "aporías del" nuevo orden? Quizás esta terminología otorga al fenómeno una dosisexcesiva de pasividad, comosilasnuevas repúblicasfueran incapaces deliberarse de una pasado historiográficamente percibido comoagobiante, y sin embargo nada fue menos pasivo que las decisiones conscientes de no rompercon aquel orden sino de reformarlo paulatinamente, una perspectiva con hondas raíces ilustradas. A fin de cuenta, Halperín Donghi propuso el siglo 1750-1850 como la cronología máseficazpara enfrentarse con la quiebra del orbehispáni- 
co en América, una mirada que se quedó muy poco practicada a pesar de la autoridad de su autor ${ }^{24}$.

El hecho que no hubo como en Francia un sujeto social nuevo que quiso dominar la sociedad para cambiarla no disminuye la calidad de las revoluciones americanas. La relación entre los cuerpos cambió, empezando por aquella entre ciudad y campo, las viejas élites coloniales de las capitales perdieron en muchos países su poderío en favor de las provinciales pero también éstas tuvieron que enfrentarse con los notables pueblerinos que en unos casos llegaron a la presidencia. La lucha entre "centralismo" y "federalismo" expresó sólo en parte estos nudosdelconflictopolítico-social porquelosproyectosfederalestratarondeimplementar-condisputadoséxitos-federacionesdeestados neoborbónicos, sí "soberanos" pero "centralistas". Las tensiones y los conflictosentrelosgobiernosfederalesylosestadossereprodujeronal interior de ellos, entre sus gobiernos y los municipios.

\section{Conclusiones}

Para concluir estas breves reflexiones quisieramos tocar el tema del "estado" porque nos parece que las formas y las reglas de la competición política podrían proporcionarnos nuevos matices. En primer lugar una cuestión metodológica recordando otra vez a Bobbio: el concepto de"estado"depende heurísticamente de criterios analíticos de oportunidad y no de verdad, algo que Max Weber subscribería. Si el concepto es "ancho" nos proporciona ciertos resultados, si es"estrecho", otros, porque al complicar las variables cambia la cronología. Si se quiere hablar de un "estado" decimonónico en América, sin, más el objetodeestudioesdiferentedelquedefineeltérmino"estadomoderno" que en el contexto internacional decimonónico tuvo su pivote en la administración con personalidad jurídica propria. Si se acepta este enfoque, entonces no es atrevido decir que por lo menos durante la

24 Nos referimos a DONGHI, Tulio Halperín. Reforma y disolución de los imperios ibericos. Madrid: Alianza editorial, 1985. 
primera mitad del siglo no hubo las condiciones para su desarollo. Un estado casuista hispanico es sencillamente no moderno. En Francia la lucha en contra del casuismo y la justicia del pasado empezó durante la revolución y el auge fue el primer Imperio, pero su razón no fue ni ideológica ni doctrinaria sino que se impuso por necesidad: proteger las leyes revolucionarias del "arbitrio" de los jueces. Los fundamentos de la administración nueva se implementaron expropriando la justicia ordinaria de algunos de sus atributos exclusivos, así que el "tercer poder"fue mucho más reducido en sus facultades del de la época monárquica ${ }^{25}$.Valga el ejemplo de la desamortización de la Iglesia, la ley se hizo irreversible quitando la posibilidad de hacer causas en contra.

Quizás hoy sería más oportuno seguir "buscando" la república más que al "estado", la república y sus perfiles, su naturaleza de origen ilustrada que sin el rey la volvieron no moderada, su coagulante duro en el jusnaturalismo católico en sus infinitas declinaciones posibles. Más que un "republicanismo católico" sería quizás conveniente pensar en un "catolicismo republicano" y constitucionalista. Entre el sujeto y su adjetivo hay una diferencia de peso, lo cual no minimiza en absoluto la lucha de los liberales en contra del fuero eclesiástico. El puntoesquelosliberalesheredaronel proyectoborbónico deunCampomanesydeun Jovellanos, para citarunos protagonistas destacados quesin embargo nunca pusieron en discusión el fundamento católico de la sociedad. Es un hecho que el tema católico es muy controvertido en la historiografía por las tantas memorias que evoca, y sin embargo nos parece ineludible. No se trata de rescatar ideológicamente una "tradición" en contra de otra sino de historiar un capitulo muy particular del jusnaturalismo moderno con una mirada "antropológica", capaz de reconstruir el devenir republicano de una potente visión de las relaciones entre poder y sociedad ${ }^{26}$. Estas relaciones fueron el co-

25 Véase BIGOT, Gregoire. Introduction historiografique au droit administratif despuis 1789. Paris: PUFF, 2002. p. 35-75.

26 Si no nos equivocamos, el primer historiador que planteó con fuerza el jusnatralismo como tema imprescindible fue CHIAROMONTE, José Carlos. Nación y Estado. El lenguaje político en 
agulante de la monarquía por siglos y tuvieron en la justicia soberana su campo de acción política. La república constitucional incorporó por decisión propia este campo, y hubo no pocas consecuencias para la vida republicana. El consenso masivo hacia la nueva forma de gobierno podría tener así una explicación razonable. Lo mismo vale para las formas y la difícil governance de la competición política; al no tocar el orden legal de la monarquía se implementó un dualismo: el "derecho de hacer política" fue desde el primer momento mucho más amplio que los"derechos políticos" otorgados por las constituciones. Los "pueblos" republicanos se transformaron en espacios de sociabilidad política directa, un fenómeno difícil de definir "tradicional" como si nada hubiera pasado, o como si estas formas de movilización fueran una "resistencia"a lo"nuevo". La vacatio y la independencia republicana redistribuyeron recursos políticos en forma inimaginable sólo unas décadas antes, un proceso quejustifica la vivencia del término"revolución". En fin, el hecho que la competición política se institucionalizara antes de la forma de gobierno republicana - y que este proceso fuera incorporadoporlascartas-sentólas bases dela dificil gobernabilidad de las nuevas "naciones".

En todo el continente este camino no fue posible, antes ... y después... entonces no era obviamente la legislativa...

\section{Referencias bibliográficas}

ABASOLO, Ezequiel. Las "sanas doctrinas" del doctor Castro en los tiempos de la codificación. Pervivencia de la cultura juridica indiana en la segundaedicióndelProntuariodePraticaForense.RevistadeHistoriadelDerecho, no 34, 2006, p. 13-30. ISSN 1853-1784.

ARDANAZ, Daicy. Francisco Gutierrez de Estrada: sus bibliotecas y sus escritos. Revista de Historia del Derecho, n. 2, 1974, p. 175-190.

ARTOLA,Miguel.LosorígenesdelaEspañacontemporánea.Madrid:Centrode estudios constitucionales, 1999. vol. $2^{\circ}$. 
BART, Jean; HALPÉRIN, Jean-Louis. L'impossible Code civil, 1992, préface de Pierre Chaunu. Droit et Société, $n^{\circ} 22,1992$. Transformations de l'État et changements juridiques: I'exemple de l'Amérique Latine, p. 690-695. (Coll. Histoires).

BELLINGERI, Marco. Ceti ed etnie in Yucatan. Costituzione sviluppo e crisi de una formazione interetnica fra sette e ottocento. Torino: Celid, 1990

BIGOIT,Gregoire.Introductionhistoriqueaudroitadministratiffrançaisdepuis 1789. Paris: Droit Fondamental, 2002

\section{Paris: PUFF, 2002}

Introductionhistoriografiqueaudroitadministratiffrançaisdespuis1789.

BOTANA, Natalio R. Repúblicas y monarquías. La encrucijada de la independencia. Buenos Aires: Edhasa, 2016.

BOBBIO,Norberto.Giusnaturalismoepositivismogiuridico.Milano:Edizionidi Comunità, 1965.

CARMAGNANI, Marcello. L'altro occidente. L'America Latina dall'invasione europea al nuovo millennio. Torino: Einaudi, 2003

CHIARAMONTI, Gabriella. Suffragio e rappresentanza nel Peru dell 800. Gli itinerari della sovranita (1808 1860). Turin: Otto ed., 2003.

CHIAROMONTE, José Carlos. Nación y Estado. El lenguaje político en tiempos de las independencias. Buenos Aires: Editorial Sudamericana, 2004.

CLAVERO, Bartolome. Cádiz 1812: Antropología e historiografía del individuocomosujetodeconstitución.Quadernifiorentiniperlastoriadelpensiero giuridico moderno, vol. 42, n 1, 2013, p. 201-279. ISSN 0392-1867.

DEMELASM, Marie-Danielle. La invención política: Bolivia, Ecuador, Perú en el siglo XIX. Lima: Estudos historicos, 2003

DONGHI,TulioHalperín.Reformaydisolucióndelosimperiosibericos.Madrid: Alianza editorial, 1985.

ENRIQUEZ, Lucrecia Raquel. Antonio Annino, Silencios y disputas en la historia deHispanoamérica. Historia, Santiago, v.49, n. 1, p.7-9, jun. 2016. Disponible en: <https://scielo.conicyt.cl/scielo.php?script=sci_arttext\&pid=S0717-71942016000100011\&lng=es\&nrm=iso >. Acceso en: 09 jul. 2018. http://dx.doi.org/10.4067/S0717-71942016000100011.

GENARO, García. Documentos históricos mexicanos: obra conmemorativa del primer Centenario de la Independencia de México. México: Museo Nacional de Arqueología, Historia y Etnología. México, 1910-12, t. II, 
p. 148.

GUENIFFFEY, Patrice. Le nombre et la raison. La Révolution Française et les élections. Prefacio de François Furet. 1993. Dix-huitième Siècle, $n^{\circ} 26$, 1994. p. 604-605. (Economie et politique).

GUERRA,François-Xavier.Independenciaymodernidad.Madrid:Mapre,1994.

GRUZINSKI,Serge.Lacolonisation del'imaginaire.Societésindigènesetoccidentalizatión dans le Méxique español, XVI-VIII siécles. Paris: Collection Bibliothèque des Histoires, Gallimard, 1988.

LEMPERIERE, Annick. Entre Dieu et le roi la république. Paris. (Trad. esp. Entre Dios y el rey: la república. La ciudad de México de los siglos XVI al XIX. México: Fondo de Cultura Económica, 2013).

LORENTE, Marta; GARRIGA, Carlos. La constitución jurisdiccional. Madrid: Centrol político y constitucionales, 2007.

LORENTE, Marta; VALDES, José Maria Portillo (dir.). La Constitución en el orbe hispánico (1808-1826). Madrid: Congreso de los Diputados, 2011.

MANNONI,StefanoUneetindivisible.Storiadell'accentramentoamministrativo in Francia. Vol. II: Dalla contestazione al consolidamento. Milano: Per la storia pensiero giuridico moderno, 1996.

MANNORI, Luca. Per una "preistoria" della funzione amministrativa Cultura giuridica e attività dei pubblici apparati nell'età del tardo diritto comune.Quadernifiorentiniperlastoriadelpensierogiuridicomoderno,vol.42, $\mathrm{n}^{\circ}$ 1, 2013, p. 201-279. ISSN 0392-1867.

. Centralization et fonction publique dans la penseé de l'Ancien Régime: justice, police et administración. In: PERTUÉ, Michel (ed.). L'administrationterritorialdelaFrance(1750-1940)Orléans:PressesUniversitaires d'Orléans, 1998. p. 247-257.

MOLINA, Eugenia.Lenguajey revolución:Conceptos políticos claveen el Río delaPlata, 1780-1850.Rev.hist.derecho,CiudadAutónomadeBuenosAires, n. 40, dic. 2010. Disponible en: <http://www.scielo.org.ar/scielo.php?script=sci_arttext\&pid=S1853-17842010000200010\&lng=es\&nrm=iso>. Acceso en: 09 jul. 2018.

ROMANELLI, Raffaele (dir.). How did they become voters? The history of franchise in modern European representation. La Haye: Kluwer Law International, 1998.

ROMERO, Alonso. La formación de los juristas. In: GARRIGA, Carlos (co- 
ord.).Historiayconstitución.Trayectos delconstitucionalismohispánico. México: Centro de investigación y docencia económicas, 2010.

ROSANVALLON, Pierre.Le peuple introuvable. Histoire dela souveraineté du peuple en France. Paris: Collection Bibliothèque des Histoires, 1998.

SILVA,Renan.LosilustradosdeNuevaGranada1760-1808.Genealogíadeuna comunidad de interpretación. Bogotá: Universidade Eafit, 2002.

VALDES, Jose Maria Portillo. Revolución de nación. Origenes de la cultura constitucional de España. Madrid: Boletín Oficial del Estado, 2001.

Recebido em: 28/06/2017 - Aprovado em: 20/10/2017 